\title{
Ihr liebstes Titelbild 2016
}
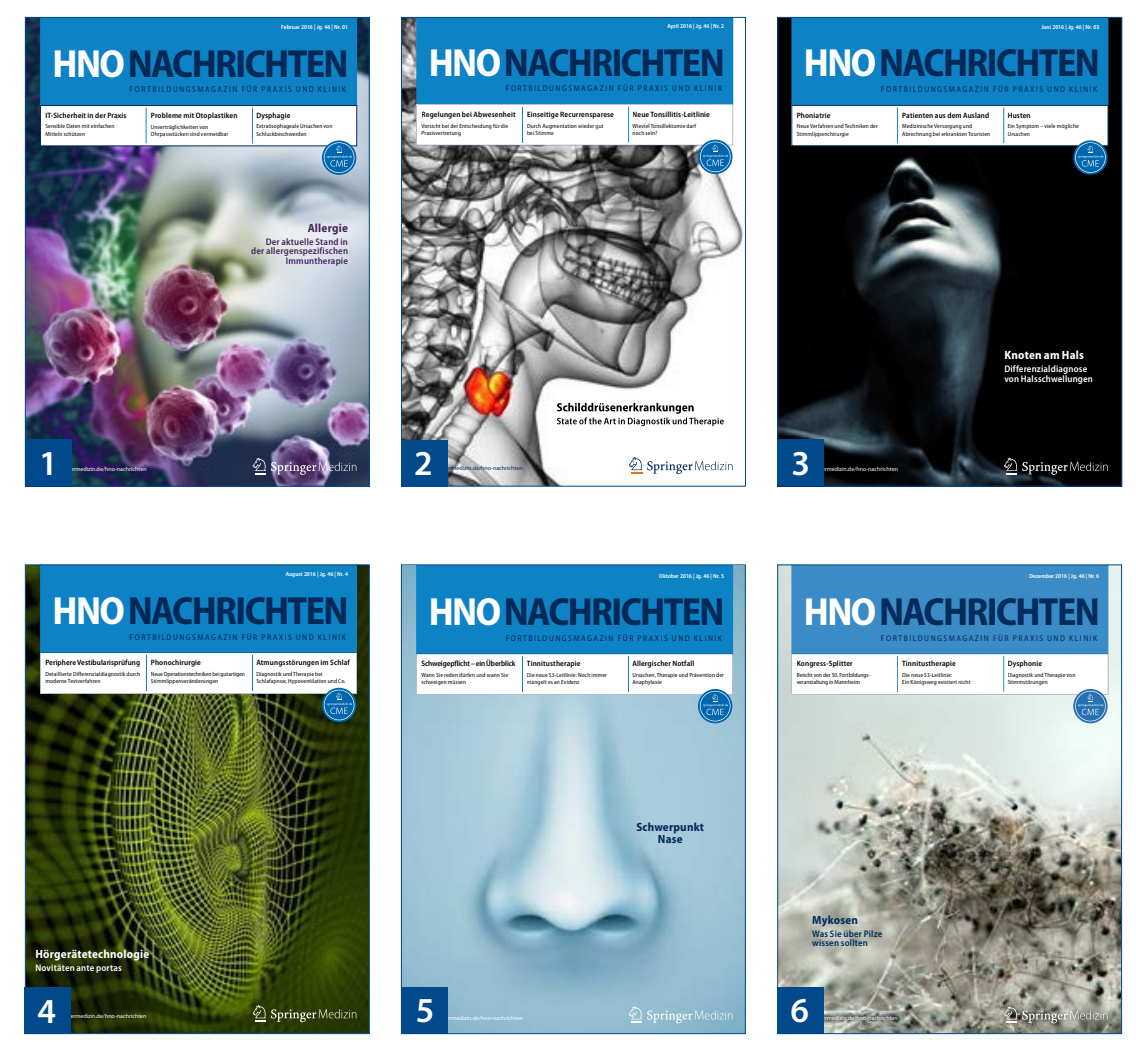

Das können Sie gewinnen

Unter allen Teilnehmern verlosen wir folgende Preise:

\section{Preis:}

(im Wert von $149 €$, unverbindliche Preisempfehlung) für die genussvolle Pause in der Praxis:

SAECO Espressomaschine Poemia HD8425/21, schwarz/ kupfer
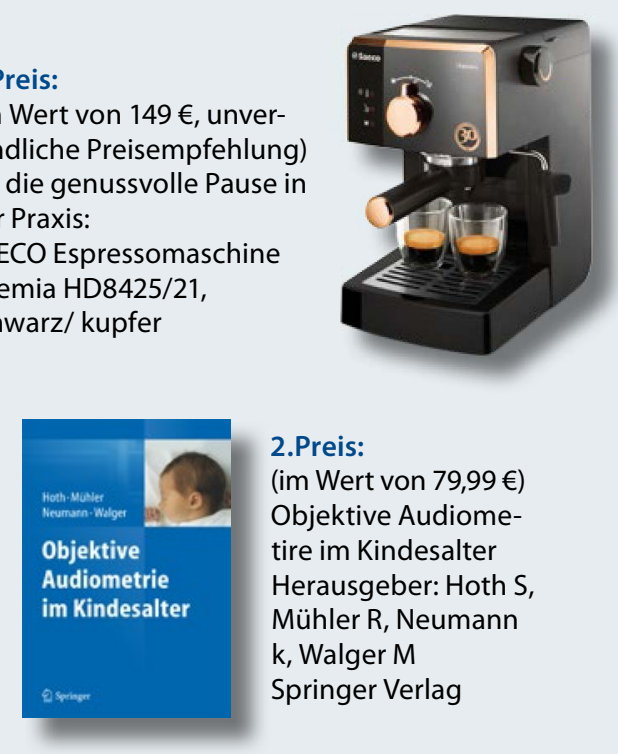

2.Preis:

(im Wert von 79,99€) Objektive Audiometire im Kindesalter Herausgeber: Hoth S, Mühler R, Neumann k, Walger M Springer Verlag

3. Preis:

(im Wert von 49,99€)

Gleichgewichtdiagnostik Herausgeber: Reiß M, Reiß G Springer Verlag

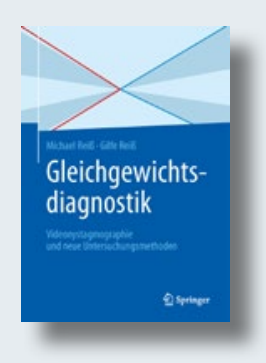

Teilnahme-Coupon bitte ausfüllen und bis 05.02. 2017 an die Redaktion faxen: Faxnr.: 089-20 304332216

Die Teilnahme ist unter www.springermedizin. de/link/11033860 auch online möglich.

Welches der abgebildeten Titelbilder der HNO Nachrichten gefällt Ihnen am besten?
Nr. $122 \quad 3 \quad 4 \quad 5 \quad 6$

Name

Vorname

Straße

Hausnummer

Postleitzahl

Ort

FAX: 08920304332216

Eine Barauszahlung der Preise ist nicht möglich. Der Rechtsweg ist ausgeschlossen. Mitarbeiter des Verlags dürfen nicht teilnehmen. 